\title{
Prognostic Accuracy of NEDA-3 in Long-term Outcomes of Multiple Sclerosis
}

Luca Prosperini, MD, PhD, Serena Ruggieri, MD, PhD, Shalom Haggiag, MD, Carla Tortorella, MD, Carlo Pozzilli, MD, PhD, and Claudio Gasperini, MD, PhD

Neurol Neuroimmunol Neuroinflamm 2021;8:e1059. doi:10.1212/NXI.0000000000001059

\section{Abstract}

\section{Background and Objectives}

To estimate the proportions of patients with relapsing-remitting multiple sclerosis who despite achieving the no evidence of disease activity-3 (NEDA-3) status in the first 2 treatment years experienced relapse-associated worsening (RAW) or progression independent from relapse activity (PIRA) in the following years.

\section{Methods}

We selected patients with NEDA-3-defined as no relapse, no disability worsening, and no MRI activity-in the first 2 years of either glatiramer acetate or interferon beta as initial treatment. We estimated the long-term probability of subsequent RAW and PIRA (considered as 2 contrasting outcomes) by cumulative incidence functions. Competing risk regressions were used to identify the baseline (i.e., at treatment start) predictors of RAW and PIRA.

\section{Results}

Of 687 patients, 224 (32.6\%) had NEDA-3 in the first 2 treatment years. After a median follow-up time of 12 years from treatment start, 58 patients (26\%) experienced disability accrual: 31 (14\%) had RAW and 27 (12\%) had PIRA. RAW was predicted by the presence of $>9$ T2 lesions (subdistribution hazard ratio $[\mathrm{SHR}]=3.92, p=0.012)$ and contrast-enhancing lesions $(\mathrm{SHR}=2.38, p=0.047)$ on baseline MRI scan and either temporary or permanent discontinuation of the initial treatment (SHR $=1.11, p=0.015)$. PIRA was predicted by advancing age (SHR $=1.05, p=0.036$ for each year increase) and presence of $\geq 1$ spinal cord lesion on baseline MRI scan $(\mathrm{SHR}=4.08, p=0.016)$.

\section{Discussion}

The adoption of NEDA-3 criteria led to prognostic misclassification in 1 of 4 patients. Different risk factors were associated with RAW and PIRA, suggesting alternative mechanisms for disability accrual.

\section{Classification of Evidence}

This study provides Class II evidence that in patients with RRMS who attained NEDA-3 status, subsequent RAW was associated with baseline MRI activity and discontinuation of treatment and PIRA was associated with age and the presence of baseline spinal cord lesions.

\author{
Correspondence \\ Dr. Prosperini \\ luca.prosperini@gmail.com
}

MORE ONLINE

(III) Class of Evidence

Criteria for rating

therapeutic and diagnostic

studies

NPub.org/coe

From the Department of Neurosciences (L.P., S.H., C.T., C.G.), S. Camillo-Forlanini Hospital; Department of Human Neurosciences (S.R., C.P.), Sapienza University; and Neuroimmunology Unit (S.R.), Santa Lucia Foundation, Rome, Italy.

Go to Neurology.org/NN for full disclosures. Funding information is provided the end of the article.

The Article Processing Charge was funded by the authors.

This is an open access article distributed under the terms of the Creative Commons Attribution-NonCommercial-NoDerivatives License 4.0 (CC BY-NC-ND), which permits downloading and sharing the work provided it is properly cited. The work cannot be changed in any way or used commercially without permission from the journal. 


\section{Glossary}

CELs = contrast-enhancing lesions; CIF = cumulative incidence function; DMTs = disease-modifying treatments; EDSS = Expanded Disability Status Scale; GA = glatiramer acetate; IFNB = Interferon beta; NEDA-3 = no evidence of disease activity-3; PIRA = progression independent of relapse activity; RAW = relapse-associated worsening; RRMS = relapsing-remitting multiple sclerosis; $\mathbf{S H R}=$ subdistribution hazard ratio; $\mathbf{M S}=$ multiple sclerosis.

The no evidence of disease activity-3 (NEDA-3), defined as no relapse, no disability increase, and no MRI activity, is deemed to be a treat-to-target strategy of disease-modifying treatments (DMTs) for relapsing-remitting multiple sclerosis (RRMS). ${ }^{1}$ Achieving the NEDA-3 status in the first 2 treatment years was shown to hold $80 \%-90 \%$ positive predictive value for the absence of longer-term disability accrual in the following years. ${ }^{2}$ Nevertheless, whether NEDA-3 actually represents a reliable surrogate marker of disease activity-free status is still debated. ${ }^{3,4}$

Growing data suggest that a multiple sclerosis (MS)related disability increase may occur not only as relapseassociated worsening (RAW) but also as progression independent of relapse activity (PIRA). ${ }^{5}$ This latter outcome, also called "silent progression," ${ }^{6}$ has been reported at a rate of $2 \%-5 \%$ per year ${ }^{6}$ and can be observed over time in those patients who keep the NEDA-3 status in the first treatment years. ${ }^{7}$ Therefore, some authors have proposed a paradigm shift in the assessment of disability progression, which is based not only on clinical relapses and focal MRI activity but also on measures of neurodegeneration. ${ }^{8}$ This may allow in identifying patients at risk of relentless progression of disability even when inflammatory activity is not evident. ${ }^{4,8}$

To date, only a single post hoc analysis of 2 randomized clinical trials (OPERA I and II) has distinguished the rates of RAW and PIRA in patients with RRMS treated with interferon beta (IFNB) or ocrelizumab, highlighting that the most disability accumulation was not associated with overt clinical relapses. ${ }^{5}$ Given the current uncertainty in defining the long-term predictive value of the NEDA-3 status, we designed a retrospective study with the following aims: (1) to estimate the proportions of patients with NEDA-3 in the first 2 treatment years experiencing PIRA and RAW in the subsequent years and (2) to identify factors associated with RAW and PIRA, respectively.

\section{Methods}

\section{Study Design and Participants}

This was an independent, 2-center, retrospective cohort study based on data collected in the real-world setting. We analyzed data of patients diagnosed with RRMS according to McDonald criteria $^{9}$ and their following revisions ${ }^{10,11}$ and those regularly attending 2 tertiary MS Centres in Rome (S. Camillo-Forlanini Hospital and S. Andrea Hospital, Rome, Italy).
We collected data of patients with RRMS according to the following criteria:

1. Patients received any formulation of either glatiramer acetate (GA) or IFNB as initial treatment.

2. An Expanded Disability Status Scale (EDSS) ${ }^{12}$ score $<3.0$ at treatment start (henceforth defined as "baseline") evaluated at least 3 months apart from a relapse.

3. Regular at least biannual clinical visits from treatment start including EDSS scoring performed by certified neurologists (neurostatus.net).

4. Complete MRI data on brain and spinal cord at baseline (within 1 month before treatment start) and after 1 and 2 years $( \pm 1$ month $)$ since treatment start acquired with the same magnet in each patient according to established guidelines. $^{13-15}$

5. A minimum of 10 years of follow-up from initial DMT start.

We chose to include only patients who started injectable DMTs to obtain long-term data, given that oral DMTs were available only after 2013 in Europe (therefore missing the 10year follow-up needed for our study).

\section{Standard Protocol Approvals, Registrations, and Patient Consents}

We gathered all data after obtaining an informed consent from each participant and after notification to our institutional ethical committee (Comitato Etico Lazio 1; e-mail: comitatoeticolazio1.it) that provided exemption of approval for noninterventional retrospective studies. In no way, this study did interfere in the care received by patients. Anonymized data presented in this article will be made available by a reasonable request of a qualified investigator (requests should be sent to the first author: luca.prosperini@gmail.com).

\section{Measures of Disease Activity}

To conform with the main purpose of our study, the main analysis was focused only on patients who had NEDA-3 in the first 2 years of their initial treatment. The NEDA-3 status was identified by the absence of the following parameters: clinical relapses, 6-month confirmed increase in EDSS score, and MRI activity. ${ }^{1}$

A clinical relapse was defined as any new neurologic symptom not associated with fever or infection lasting for at least 24 hours and accompanied by new neurologic signs or symptoms. ${ }^{9-11} \mathrm{~A}$ confirmed disability increase was defined as 1.5 -point increase (if the baseline EDSS score was 0), 1.0-point increase (if the 
baseline EDSS score was <5.5), or 0.5-point increase (if the baseline EDSS score was $\geq 5.5$ ) confirmed 6 months apart. ${ }^{16}$

MRI activity included the presence of contrast-enhancing lesions (CELs) and new T2-hyperintense lesions (as compared with the baseline scan) on brain and spinal cord. CELs were detected on T1-weighted spin echo axial (for brain imaging) and sagittal (for spinal cord imaging) images after gadoliniumdiethylenetriamine penta-acetic acid administration sequences. ${ }^{13} \mathrm{New}$ focal T2 lesions were detected on axial T2/ proton density-weighted fast spin echo and fluid-attenuated inversion recovery sequences (for brain imaging) and sagittal and axial T2-weighted fast spin echo and T2-short-tau inversion recovery (for spinal cord imaging). Enlarging T2 lesions were not counted because of the poor between-rater agreement for this metric under routine clinical setting. ${ }^{14,17}$

\section{Outcome Definition}

We analyzed 2 different outcomes: RAW, defined as sustained disability worsening occurring within 3 months after a clinical relapse, and PIRA, defined as sustained increase in disability occurring in patients who were relapse-free. ${ }^{5}$ Although RAW and PIRA are considered 2 nonmutually exclusive drivers for long-term disability accrual, in this study, we considered PIRA and RAW as 2 competing outcomes (i.e., the occurrence of one precludes the other one and vice versa), whichever came first.

Both outcomes were retrospectively identified on the basis of disability increase, as afore defined. ${ }^{16}$ Long-term disability accrual due to RAW or PIRA had to be confirmed in at least 2 consecutive visits and sustained (stable or higher) over the entire follow-up.

\section{Statistical Analysis}

Descriptive data were presented as count (proportion) for categorical variables and mean \pm SD or median (interval) for continuous variables. Between-group differences were tested by the Fisher exact test or the Mann-Whitney $U$ test, as appropriate.

Baseline variables of interest included the following: sex (female or male), age (years), comorbidity (presence or absence), onset symptom (afferent or efferent), disease duration (years), EDSS score, pretreatment annualized relapse rate, CELs on brain and/or spinal MRI scan (absence or presence), brain lesion count ( $\leq 9$ or $>9 \mathrm{~T} 2$ lesions), infratentorial lesion (absence or presence), and spinal cord lesion (absence or presence).

The first aim of this study was explored by estimating the probabilities of RAW and PIRA using the cumulative incidence function (CIF) method. ${ }^{18}$ We also compared the proportions of patients who experienced PIRA and RAW in the subgroup of patients with NEDA- 3 status and in those who did not maintain their NEDA-3 status at year 2 postinitial DMT start.
For the second aim of this study, we ran 2 competing risk analyses according to the Fine-Gray model ${ }^{19,20}$ to estimate the subdistribution hazard ratio (SHR) of each covariate of interest on the CIF for PIRA and RAW. Both models were adjusted by calendar year at treatment start to account for revisions of diagnostic criteria over time. ${ }^{9-11}$ Temporary interruption ( $\geq 6$ months) or permanent discontinuation of DMT was also inserted in the models as time-varying covariate to explore the effect of treatment withdrawal on the risk of PIRA and RAW. Two-sided $p$ values $<0.05$ were considered as significant.

\section{Results}

\section{Participants}

Of 687 patients who started a platform DMT before 2010, we identified 224 (32.6\%) with NEDA-3 in the first 2 treatment years with subcutaneous IFNB-1a $(\mathrm{n}=111)$, IM IFNB-1a ( $\mathrm{n}$ $=47)$, subcutaneous IFNB-1b $(\mathrm{n}=41)$, or subcutaneous GA $(\mathrm{n}=25)$. Their baseline characteristics are summarized in Table 1. Patients with evidence of disease activity during the initial 2 years of treatment $(n=463)$ were younger and had greater disability and more pretreatment relapses and CELs than those with NEDA-3 $(p \leq 0.01)$.

\section{Follow-up}

The 224 patients with NEDA- 3 in the first 2 treatment years were followed up for a median time of 12 (range: 10-19) years from initial DMT start. The median frequency of MRI assessments was approximately 1 scan every 1.5 years per

Table 1 Baseline Clinical Characteristics of the Study Sample $(n=224)$

\begin{tabular}{lc}
\hline Male sex & $69(31)$ \\
\hline Mean (SD) age, y & $34.6(8.8)$ \\
\hline Comorbidity $^{\mathbf{a}}$ & $40(18)$ \\
\hline Efferent symptom onset $^{\mathbf{b}}$ & $70(31)$ \\
\hline Mean (SD) disease duration, y & $4.6(2.4)$ \\
\hline Median (range) EDSS score & $1.5(0-3.0)$ \\
\hline Mean (SD) annualized relapse rate & $0.9(0.75)$ \\
\hline Contrast-enhancing lesions & $124(55)$ \\
\hline >9 brain lesions & $140(62)$ \\
\hline Infratentorial lesions & $58(26)$ \\
\hline Spinal cord lesions & $93(41)$ \\
\hline
\end{tabular}

Abbreviation: EDSS = Expanded Disability Status Scale.

All values are $\mathrm{n}(\%)$, unless indicated otherwise.

a Forty-four comorbid conditions in 40 patients, as follows: autoimmune thyroid disease $(n=16)$, arterial hypertension $(n=6)$, mood disorders $(n=6)$, neoplasms $(n=5)$, migraine $(n=4)$, hepatitis $B(n=2)$, substance misuse $(n=$ $2)$, chronic cholecystitis $(n=1)$, endocarditis $(n=1)$, and psoriasis $(n=1)$.

${ }^{b}$ Central paresis $(n=42)$, diplopia $(n=19)$, ataxia $(n=8)$, and bladder dysfunction $(n=1)$. 
Table 2 Follow-up Data After the First 2 Treatment Years by Long-term Outcomes

\begin{tabular}{|c|c|c|c|c|c|}
\hline & \multirow{2}{*}{$\begin{array}{l}\text { Whole sample, } \\
n=224\end{array}$} & \multirow{2}{*}{$\begin{array}{l}\text { No disability, } \\
\text { accrual } n=166\end{array}$} & \multicolumn{2}{|c|}{ Disability accrual } & \multirow[b]{2}{*}{$p$ Value } \\
\hline & & & RAW, $n=31$ & PIRA, $n=27$ & \\
\hline Relapses & $78(35)$ & $45(27)$ & $31(100)$ & $2(7)$ & $0.001^{\mathrm{a}}$ \\
\hline MRI activity & $87(39)$ & $55(33)$ & $28(90)$ & $3(11)$ & $0.001^{a}$ \\
\hline Median (interval) no. of MRI scans & $8(5-17)$ & $8(5-15)$ & $8(5-17)$ & $8(5-13)$ & - \\
\hline $\begin{array}{l}\text { Temporary interruption or } \\
\text { permanent discontinuation }\end{array}$ & $50(22)$ & $33(20)$ & $12(39)$ & $5(18)$ & $0.05^{\mathrm{b}}$ \\
\hline
\end{tabular}

Abbreviations: PIRA = progression independent from relapse activity; RAW = relapse-associated worsening.

All values are $n(\%)$, unless indicated otherwise.

a $p \leq 0.001$ RAW vs no disability accrual and PIRA.

${ }^{\mathrm{b}} p<0.05$ RAW vs no disability accrual.

patient. Despite their NEDA-3 status in the first 2 years, 79 (35\%) experienced clinical relapses and 87 (39\%) had MRI activity over the following years.

Of the 224 patients, 42 (19\%) changed their initial treatment after a median time of 6 (range 3-10) years: 28 switched to oral DMTs because of "needle fatigue" (22 to dimethyl fumarate and 6 to teriflunomide) and 14 escalated to high-effective DMTs for clinical and MRI activities (10 to fingolimod and 4 to natalizumab). Along the follow-up, after a median time of 9 (range 2-17) years, 38 patients (17\%) temporarily interrupted ( 26 because of pregnancy and 12 for patient's decision) and 12 patients $(5 \%)$ permanently discontinued their initial DMT for loss of adherence. Table 2 summarizes the follow-up data after the first 2 treatment years.

\section{Outcomes}

Of the 224 patients, 58 patients (26\%) experienced disability accrual: 31 (14\%) had RAW and 27 (12\%) had PIRA (Figure 1). The median time from treatment start to RAW and

Figure 1 Study Flowchart of Patients' Disposition

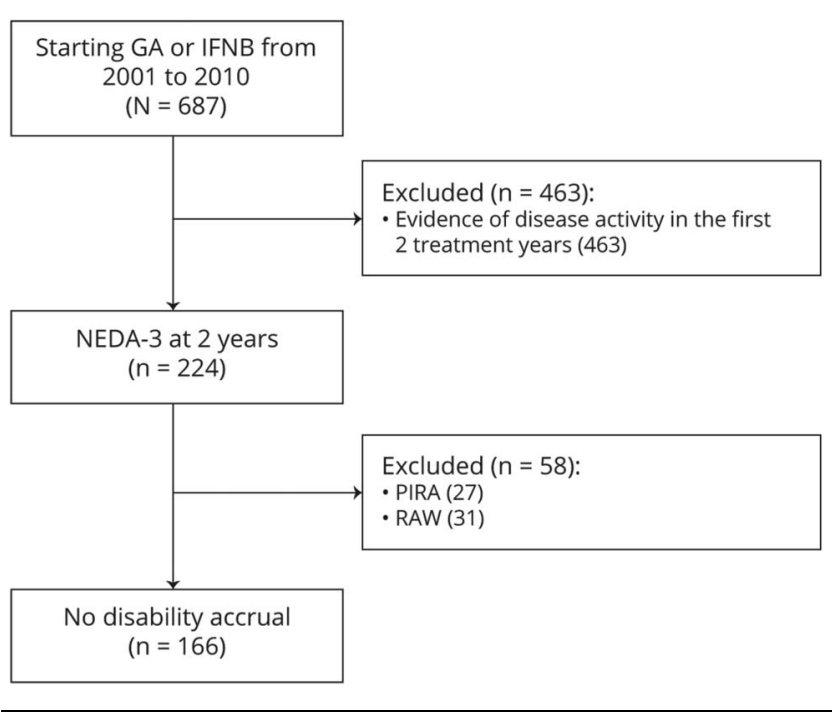

to PIRA was 10 (range: $3-18$ ) and 9 (range: 4-15) years, respectively $(p=0.51)$. Figure $2 \mathrm{~A}$ shows the CIF for experiencing PIRA and RAW. The median EDSS change over time did not differ between RAW and PIRA subgroups (Figure 2B).

After the first 2 treatment years, 47 patients (21\%) experienced relapses not associated with disability worsening. MRI activity was more frequent in the RAW subgroup (90\%) than in the PIRA subgroup (11\%) and in patients without disability accrual (33\%). The median number of scans per patient did not differ across subgroups.

In the PIRA subgroup, MRI activity was detected from 2 to 5 years in advance of the disability accrual; therefore, we believe a causal direct connection unlikely. The rate of temporary interruption or permanent discontinuation of the platform DMT during the follow-up was higher in the RAW subgroup (39\%) than in the remaining subgroups with PIRA $(18 \%)$ and without disability accrual (20\%), as summarized in Table 2.

As additional analysis, we found RAW more frequent in patients with early disease activity $(n=463)$ than in those with NEDA-3 $(\mathrm{n}=224)$ in the first 2 treatment years $(p<0.001)$, whereas there was no difference in patients with PIRA ( $p=$ 0.54 ) (Figure 3). Notably, there was no between-group difference in follow-up time $(p=0.77)$.

\section{Competing Risk Analyses}

We found different baseline factors associated with RAW and PIRA in patients with NEDA-3 in the first 2 treatment years (Table 3). The risk of RAW was associated with the detection of CELs (adjusted SHR $=2.38, p=0.047$ ), the presence of $>9$ T2 lesions (adjusted SHR $=3.92, p=0.012$ ), and the event of both temporary interruption and permanent discontinuation of the initial DMT (adjusted SHR $=1.11, p=0.015$ ).

The risk of PIRA was associated with increasing age (adjusted SHR $=1.05$ for each year increase, $p=0.036$ ) and the presence of spinal cord lesions at baseline MRI scan (adjusted SHR $=4.08, p=0.016)$. Neither temporary interruption nor 
Figure 2 (A) Cumulative Incidence Functions of Progression Relapse-Associated Worsening (RAW) and Progression Independent From Relapse Activity (PIRA) in Patients With No Evidence of Disease Activity-3 (NEDA-3) After 2 Years From Treatment Start; (B) Disability Changes, Expressed as Step of Expanded Disability Status Scale (EDSS), by Long-term Outcomes $(n=224)$
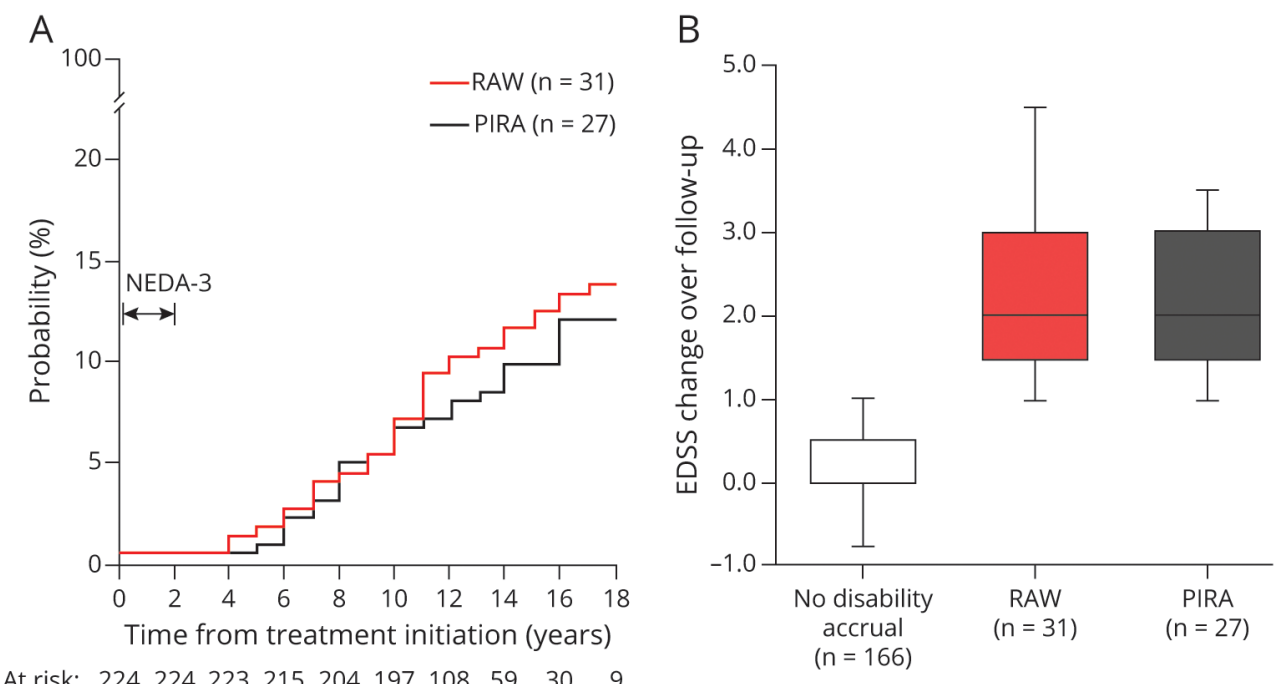

permanent discontinuation of the initial DMT influenced the risk of PIRA. These findings did not substantially change even after exploring cause-specific HR by classic Cox regression analyses (data not shown).

Figure 3 Proportion of Patients Experiencing RelapseAssociated Worsening (RAW) and Progression Independent From Relapse Activity (PIRA) by Disease Activity After 2 Years From Treatment Start (Median Follow-up Time of 12 Years)

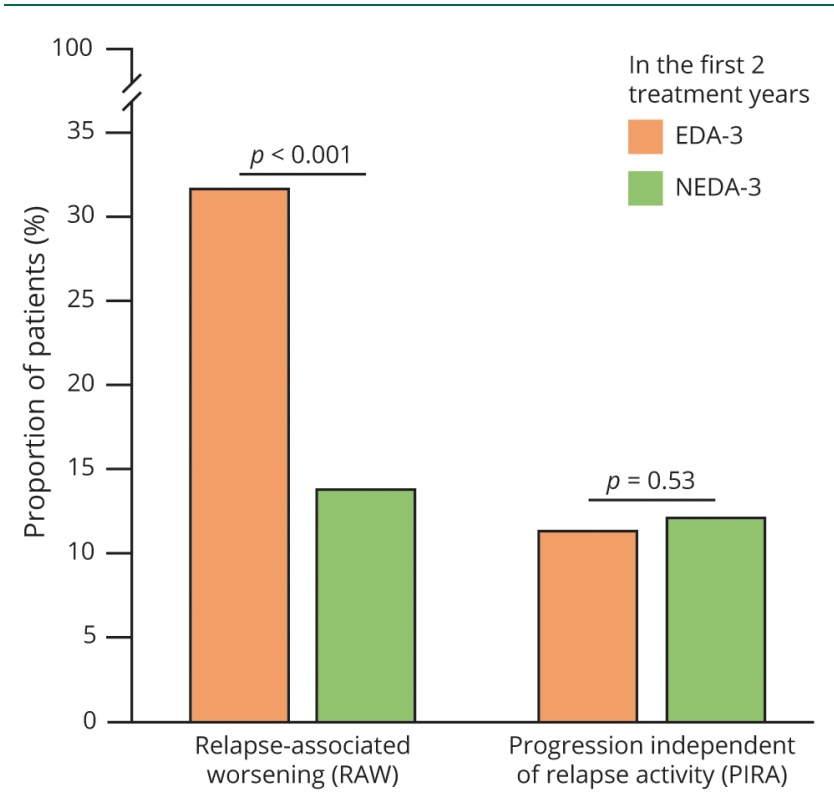

EDA-3 = evidence of disease activity-3 ( $n=463)$; NEDA-3 = no evidence of disease activity-3 $(n=224)$.

\section{Discussion}

In this study, we explored the long-term outcomes of patients who kept the NEDA-3 status in the first 2 treatment years with their platform DMT. The novelty of our work stands in the competitive risk analysis of RAW and PIRA as 2 different drivers of disability accrual. Although other authors have already approached this issue, ${ }^{2,7,21-23}$ the competing risk of experiencing RAW or PIRA has never been purposefully investigated before in the real-world setting. We found approximately 3 in 4 patients correctly classified and 1 in 4 patients misclassified on the basis of the NEDA- 3 construct because they experienced long-term disability accrual despite achieving the NEDA-3 status in the first 2 treatment years. Although most patients were correctly classified, our finding is clinically relevant because a certain amount of patients had an (apparent) early optimal treatment response, but a long-term disability accrual was nevertheless observed. We should also consider that previous studies demonstrated long-term clinical stability in patients with minimal evidence of disease activity, $^{22,24}$ thus further reinforcing skepticism about the long-term prognostic value of the NEDA-3, which is mainly weighted on neuroinflammation and focal demyelination parameters rather than on other measures assessing subtle diffuse inflammatory damage and neurodegeneration. ${ }^{4,25}$ In addition to relapses, disability worsening, and MRI activity, the inclusion of brain volume change over time (the so-called NEDA-4) can provide a more comprehensive and balanced measure for predicting long-term disease evolution. ${ }^{26}$ However, the longitudinal brain volume assessment is considered unreliable at present ${ }^{14}$; therefore, our findings reiterate the urgent need for clinical or paraclinical indicators of subtle disability accrual. ${ }^{4}$ 
Table 3 Competing Risk Regression Analyses for RAW and PIRA on 224 Patients With No Evident Disease Activity After the First 2 Years of Treatment

\begin{tabular}{|c|c|c|c|c|}
\hline & \multicolumn{2}{|l|}{$\operatorname{RAW}(n=31)$} & \multicolumn{2}{|l|}{ PIRA (n = 27) } \\
\hline & Adjusted SHR (95\% Cls) & $p$ Value & Adjusted SHR (95\% Cls) & $p$ Value \\
\hline Male sex & $1.84(0.89-3.82)$ & 0.10 & $0.77(0.28-2.08)$ & 0.60 \\
\hline Age (each y) & $1.02(0.97-1.07)$ & 0.51 & $1.05(1.01-1.10)$ & 0.036 \\
\hline Comorbidity & $0.78(0.26-2.29)$ & 0.65 & $1.88(0.84-4.26)$ & 0.13 \\
\hline Efferent symptom onset & $1.72(0.62-4.64)$ & 0.29 & $1.06(0.44-2.56)$ & 0.89 \\
\hline Disease duration (each y) & $1.00(0.91-1.08)$ & 0.93 & $1.03(0.96-1.10)$ & 0.46 \\
\hline EDSS score (each step) & $0.79(0.49-1.26)$ & 0.32 & $1.37(0.77-2.41)$ & 0.28 \\
\hline Annualized relapse rate (each unit) & $1.25(0.56-2.76)$ & 0.58 & $0.99(0.39-2.52)$ & 0.98 \\
\hline$>9$ brain lesions & $3.92(1.36-11.29)$ & 0.012 & $0.88(0.20-3.86)$ & 0.87 \\
\hline Infratentorial lesions & $1.28(0.49-3.12)$ & 0.61 & $1.52(0.66-3.53)$ & 0.33 \\
\hline Spinal cord lesions & $1.11(0.46-2.70)$ & 0.81 & $4.08(1.29-12.87)$ & 0.016 \\
\hline Contrast-enhancing lesions & $2.38(1.01-5.63)$ & 0.047 & $0.62(0.26-1.49)$ & 0.29 \\
\hline $\begin{array}{l}\text { Treatment interruption } \\
\text { (time-varying covariate) }\end{array}$ & $1.11(1.02-1.21)$ & 0.015 & $1.04(0.94-1.16)$ & 0.43 \\
\hline
\end{tabular}

Abbreviations: Cls = confidence intervals; EDSS = Expanded Disability Status Scale; PIRA = progression independent from relapse activity; RAW = relapseassociated worsening; SHR = subdistribution hazard ratio.

As today, the most promising strategy seems to be a multimodal approach that integrates serologic (neurofilaments) and nonconventional MRI biomarkers, including brain and spinal cord atrophy, smoldering and cortical lesions, ${ }^{27}$ and neurophysiologic measurements. Unfortunately, all these biomarkers are still not applicable to routine clinical practice. $^{4}$

In our study, long-term disability accrual was attributable to RAW in $14 \%$ of patients and to PIRA in $12 \%$ of patients. These findings are somewhat conflicting with previous literature data showing that PIRA events comprised most (approximately 70\%-90\%) of all disability accrual events in a follow-up time of $2-10$ years. ${ }^{5,6,28}$ These discrepancies can be explained by differences in study design (real-world vs post hoc analyses of randomized clinical trials) and PIRA definition. We calculated EDSS changes using a fixed reference value rather than the more sensitive roving value, possibly leading to an underestimation of the proportion of patients with PIRA as compared with previous studies. ${ }^{28,29}$ Other studies adopted composite scores to define PIRA events, including the 25 -foot walking test, the 9-hole peg test, and the symbol digit modalities test. ${ }^{5,6}$

In our sample, RAW was associated with focal neuroinflammation parameters such as the presence of $>9 \mathrm{~T} 2$ brain lesions and CELs on baseline MRI scan, whereas the risk of PIRA was mainly related to advancing age and spinal cord lesions. These findings hold clinically relevant implications because RAW results to be somewhat prevented by the currently available DMTs, whereas PIRA does not seem to be affected by platform treatments. This latter hypothesis is supported by the additional analysis revealing that the initial treatment response predicted the long-term risk of RAW but had no effect on the risk of PIRA. In other words, although we analyzed only patients with NEDA-3 in the first 2 treatment years-thus selecting a sample with an inherent better prognosis - the proportions of PIRA did not differ between patients with NEDA-3 and those who did not in the first 2 treatment years (Figure 3). ${ }^{6,7}$

Permanent discontinuation or even temporary interruption of the platform DMT resulted associated with an increased risk of RAW. If, on one hand, this is quite expected on the basis of existing literature, ${ }^{30-32}$ on the other hand, our finding conflicts with other authors who observed better outcomes in those patients who withdrew their DMTs after a prolonged period without relapses. ${ }^{33-35}$ However, our data discourage permanent discontinuation or even temporary interruption of the initial DMT even in patients who early achieved the NEDA-3 status and remained stable over time.

Basically, PIRA can be comparable with the so-called silent progression. ${ }^{6}$ Because it occurs in the absence of clinical relapses and MRI activity, silent progression may escape routine clinical assessment, resulting in a misperception of the DMT effectiveness. ${ }^{8}$ Age at treatment start and presence of spinal cord lesions were the main factors associated with PIRA in apparently stable patients. Emerging evidence supports that both the clinical onset of the progressive phase and its 
pathologic hallmarks are dependent on age-related processes. ${ }^{36,37}$ Moreover, increasing age was shown to be associated with a smaller treatment effect of the currently available DMTs. ${ }^{38}$

High rates of spinal cord lesions have been associated with a more aggressive disease course, regardless of disease duration. ${ }^{39}$ Our finding is in line with this latter evidence because the damage of long neural pathways, representing functional "bottlenecks" (including the efferent corticospinal tracts for movement), resulted to be associated with neurologic impairment and long-term disability. ${ }^{40}$

The limitations of our study are intrinsic in its retrospective and observational design, in addition to the relatively small sample size, and the inclusion of only patients initially treated with either GA or IFNB (that was required to obtain longterm data). Consequently, our findings should be limited only to patients under injectable DMTs and cannot be generalized to the newer oral DMTs.

Our long-term outcome was based only on sustained EDSS increase, not encompassing other relevant measures, e.g., upper limb deficit and cognitive impairment. ${ }^{5}$

Another concern is the retrospective distinction of a "bona fide" progression from a permanent "inflammation"-related disability worsening. ${ }^{37}$ According to the last classification of clinical disease course, progression without activity should be determined not only by the absence of clinical relapses but also by the absence of MRI activity assessed at least annually. ${ }^{41}$ In our study, MRI activity was uncommon in the PIRA subgroup (only 11\%) and was always detected several years before the disability accrual. Unfortunately, considering the real-world setting, we cannot rule out that some PIRA events could have been accompanied by MRI activity. Furthermore, our study is based on the past clinical practice of performing an MRI scan at baseline and after 1 and 2 years, whereas current guidelines recommend a rebaseline MRI scan around 3-6 months after baseline to exclude residual disease activity due to the gap between the treatment start and its actual effect. ${ }^{4}$

We are confident that our study has also some strengths, including the long-term follow-up and the availability of serial MRI scans of the brain and spinal cord with the same scanner for each patient that minimized the potential bias in estimating new T2 lesions. In addition, we adopted a statistical approach (competing risk analysis), which allowed us to explore contrasting outcomes (i.e., disability accrual related to either relapse or progression).

Our study suggests that NEDA-3 does not ensure long-term clinical stability because disability accrual may occur as both RAW and PIRA in a certain proportion of patients. Although RAW can be prevented by high-effective DMTs and by promoting treatment adherence, PIRA largely depends on nonmodifiable (at present) risk factors such as agerelated processes and MS-related damage in neural pathways representing functional bottlenecks. Future efforts should thereby focus on better elucidating mechanisms leading to neurodegeneration and neurorestoration to identify the best candidate treatments for slowing disease progression and promoting functional recovery.

\section{Study Funding}

The authors report no targeted funding.

\section{Disclosure}

L. Prosperini: consulting fees from Biogen, Novartis, and Roche; speaker honoraria from Biogen, Genzyme, MerckSerono, Novartis, and Teva; travel grants from Biogen, Genzyme, Novartis, and Teva; and research grants from the Italian MS Society (Associazione Italiana Sclerosi Multipla) and Genzyme. S. Ruggieri: personal fees and nonfinancial support from Biogen, Genzyme, Merck-Serono, Novartis, and Teva. S. Haggiag: travel funding and/or speaker honoraria from Biogen, Roche, Genzyme, Novartis, and CSL Behring. C. Tortorella: honoraria for speaking and travel grants from Biogen, Sanofi-Aventis, Merck Serono, Bayer-Schering, Teva, Genzyme, Almirall, and Novartis. C. Pozzilli: scientific advisory boards for Actelion, Biogen, Genzyme, Hoffmann-La Roche Ltd, Merck-Serono, Novartis, Sanofi, and Teva and consulting and/or speaking fees, research support, and travel grants from Allergan, Almirall, Biogen, Genzyme, HoffmannLa Roche Ltd, Merck-Serono, Novartis, Sanofi, and Teva. C. Gasperini: fees as invited speaker or travel expenses for attending meeting from Biogen, Merck-Serono, Teva, Sanofi, Novartis, and Genzyme. Go to Neurology.org/NN for full disclosures.

\section{Publication History}

Received by Neurology: Neuroimmunology \& Neuroinflammation May 24, 2021. Accepted in final form July 6, 2021.

Appendix Authors

\begin{tabular}{lll}
\hline Name & Location & Contribution \\
\hline Luca & Department of & $\begin{array}{l}\text { Drafting/revision of the article } \\
\text { Prosperini, }\end{array}$ \\
MD, PhD & Seurosciences, & $\begin{array}{l}\text { writing for content; major role } \\
\text { S. Camillo-Forlanini }\end{array}$ \\
& Hospital, Rome, Italy & $\begin{array}{l}\text { in the acquisition of data; } \\
\text { study concept or design; and } \\
\text { analysis or interpretation of } \\
\text { data }\end{array}$ \\
&
\end{tabular}

Serena Department of Human

Ruggieri, Neurosciences, Sapienza

MD, PhD University, Rome, Italy Neuroimmunology Unit, Santa Lucia Foundation, Rome, Italy

\begin{tabular}{lll}
\hline Shalom & Department of & Drafting/revision of the article \\
Haggiag, & Neurosciences, & for content, including medical \\
MD & S. Camillo-Forlanini & writing for content; study \\
Hospital, Rome, Italy & $\begin{array}{l}\text { concept or design; and } \\
\text { analysis or interpretation of } \\
\text { data }\end{array}$
\end{tabular}

Drafting/revision of the article for content, including medical writing for content; major role in the acquisition of data; and study concept or design

data 
Appendix (continued)

\begin{tabular}{|c|c|c|}
\hline Name & Location & Contribution \\
\hline $\begin{array}{l}\text { Carla } \\
\text { Tortorella, } \\
\text { MD }\end{array}$ & $\begin{array}{l}\text { Department of } \\
\text { Neurosciences, } \\
\text { S. Camillo-Forlanini } \\
\text { Hospital, Rome, Italy }\end{array}$ & $\begin{array}{l}\text { Drafting/revision of the article } \\
\text { for content, including medical } \\
\text { writing for content; major role } \\
\text { in the acquisition of data; and } \\
\text { analysis or interpretation of } \\
\text { data }\end{array}$ \\
\hline $\begin{array}{l}\text { Carlo } \\
\text { Pozzilli, } \\
\text { MD, PhD }\end{array}$ & $\begin{array}{l}\text { Department of Human } \\
\text { Neurosciences, Sapienza } \\
\text { University, Rome, Italy }\end{array}$ & $\begin{array}{l}\text { Drafting/revision of the article } \\
\text { for content, including medical } \\
\text { writing for content; major role } \\
\text { in the acquisition of data; and } \\
\text { analysis or interpretation of } \\
\text { data }\end{array}$ \\
\hline $\begin{array}{l}\text { Claudio } \\
\text { Gasperini, } \\
\text { MD, PhD }\end{array}$ & $\begin{array}{l}\text { Department of } \\
\text { Neurosciences, } \\
\text { S. Camillo-Forlanini } \\
\text { Hospital, Rome, Italy }\end{array}$ & $\begin{array}{l}\text { Drafting/revision of the article } \\
\text { for content, including medical } \\
\text { writing for content; study } \\
\text { concept or design; and } \\
\text { analysis or interpretation of } \\
\text { data }\end{array}$ \\
\hline
\end{tabular}

\section{References}

1. Giovannoni G, Tomic D, Bright JR, Havrdová E. "No evident disease activity": the use of combined assessments in the management of patients with multiple sclerosis. Mult Scler. 2017;23(9):1179-1187.

2. Rotstein DL, Healy BC, Malik MT, Chitnis T, Weiner HL. Evaluation of No evidence of disease activity in a 7-year longitudinal multiple sclerosis cohort. JAMA Neurol. 2015;72(2):152-158.

3. Hegen H, Bsteh G, Berger T. "No evidence of disease activity"-is it an appropriate surrogate in multiple sclerosis? Eur J Neurol. 2018;25(9):1107-e101.

4. Gasperini $\mathrm{C}$, Prosperini $\mathrm{L}$, Tintoré $\mathrm{M}$, et al. Unraveling treatment response in multiple sclerosis: a clinical and MRI challenge. Neurology. 2019;92(4):180-192.

5. Kappos L, Wolinsky JS, Giovannoni G, et al. Contribution of relapse-independent progression vs relapse-associated worsening to overall confirmed disability accumulation in typical relapsing multiple sclerosis in a pooled analysis of 2 randomized clinical trials. JAMA Neurol. 2020;77(9):1132-1140.

6. University of California, San Francisco MS-EPIC Team; Cree BAC, Hollenbach JA, Bove $\mathrm{R}$, et al. Silent progression in disease activity-free relapsing multiple sclerosis. Ann Neurol. 2019;85(5):653-666.

7. University of California, San Francisco MS-EPIC Team; Cree BAC, Gourraud P, Oksenberg JR, et al. Long-term evolution of multiple sclerosis disability in the treatment era. Ann Neurol. 2016;80(4):499-510.

8. Filippi M, Rocca MA. Classifying silent progression in relapsing-remitting MS. Nat Rev Neurol. 2019;15(6):315-316.

9. McDonald WI, Compston A, Edan G, et al. Recommended diagnostic criteria for multiple sclerosis: guidelines from the International Panel on the diagnosis of multiple sclerosis. Ann Neurol. 2001;50(1):121-127.

10. Polman $\mathrm{CH}$, Reingold SC, Edan G, et al. Diagnostic criteria for multiple sclerosis: 2005 revisions to the "McDonald Criteria." Ann Neurol. 2005;58(6):840-846.

11. Polman CH, Reingold SC, Banwell B, et al. Diagnostic criteria for multiple sclerosis: 2010 revisions to the McDonald criteria. Ann Neurol. 2011;69(2):292-302.

12. Kurtzke JF. Rating neurologic impairment in multiple sclerosis: an expanded disability status scale (EDSS). Neurology. 1983;33(11):1444-1452.

13. Filippi M, Rocca MA, Bastianello S, et al. Guidelines from the Italian Neurological and Neuroradiological Societies for the use of magnetic resonance imaging in daily life clinical practice of multiple sclerosis patients. Neurol Sci. 2013;34:2085-2093.

14. Wattjes MP, Rovira À, Miller D, et al. Evidence-based guidelines: MAGNIMS consensus guidelines on the use of MRI in multiple sclerosis: establishing disease prognosis and monitoring patients. Nat Rev Neurol. 2015;11(10):597-606.

15. Brisset JC, Kremer S, Hannoun S, et al. New OFSEP recommendations for MRI assessment of multiple sclerosis patients: special consideration for gadolinium deposition and frequent acquisitions. J Neuroradiol. 2020;47:250-258.

16. Río J, Nos C, Tintoré $\mathrm{M}$, et al. Defining the response to interferon-beta in relapsingremitting multiple sclerosis patients. Ann Neurol. 2006;59(2):344-352.
17. Erbayat Altay E, Fisher E, Jones SE, Hara-Cleaver C, Lee JC, Rudick RA. Reliability of classifying multiple sclerosis disease activity using magnetic resonance imaging in a multiple sclerosis clinic. JAMA Neurol. 2013;70(3):338-344.

18. Putter H, Fiocco M, Geskus RB. Tutorial in biostatistics: competing risks and multistate models. Stat Med. 2007;26(11):2389-2430.

19. Fine JP, Gray RJ. A proportional hazards model for the subdistribution of a competing risk. J Am Stat Assoc. 1999;94(446):496-509.

20. Austin PC, Fine JP. Practical recommendations for reporting Fine-Gray model analyses for competing risk data. Stat Med. 2017;36(27):4391-4400

21. Tsantes E, Curti E, Collura F, Bazzurri V, Fiore A, Granella F. Five- and seven-year prognostic value of new effectiveness measures (NEDA, MEDA and six-month delayed NEDA) in relapsing-remitting multiple sclerosis. J Neurol Sci. 2020;414: 116827.

22. Río J, Rovira À, Tintoré $\mathrm{M}$, et al. Disability progression markers over 6-12 years in interferon- $\beta$-treated multiple sclerosis patients. Mult Scler. 2018;24(3):322-330.

23. Uher T, Havrdova E, Sobisek $L$, et al. Is no evidence of disease activity an achievable goal in MS patients on intramuscular interferon beta-1a treatment over long-term follow-up? Mult Scler. 2017;23(2):242-252.

24. Prosperini L, Mancinelli C, Haggiag S, et al. Minimal evidence of disease activity (MEDA) in relapsing-remitting multiple sclerosis. J Neurol Neurosurg Psychiatry. 2020;91(3):271-277.

25. Lassmann H, Brück W, Lucchinetti CF. The immunopathology of multiple sclerosis: an overview. Brain Pathol. 2007;17(2):210-218.

26. Kappos L, De Stefano N, Freedman MS, et al. Inclusion of brain volume loss in revised measure of 'no evidence of disease activity' (NEDA-4) in relapsing-remitting multiple sclerosis. Mult Scler. 2016;22(10):1297-1305.

27. Rocca MA, Filippi M. Targeting progression in multiple sclerosis-an update. Nat Rev Neurol. 2019;15(2):62-64

28. Kappos L, Butzkueven H, Wiendl H, et al. Greater sensitivity to multiple sclerosis disability worsening and progression events using a roving versus a fixed reference value in a prospective cohort study. Mult Scler. 2018;24(7):963-973.

29. Lepore V, Bosetti C, Santucci C, Iaffaldano P, Trojano M, Mosconi P. Detection of disability worsening in relapsing-remitting multiple sclerosis patients: a real-world roving Expanded Disability Status Scale reference analysis from the Italian Multiple Sclerosis Register. Eur J Neurol. 2021;28(2):567-578.

30. Siger M, Durko A, Nicpan A, Konarska M, Grudziecka M, Selmaj K. Discontinuation of interferon beta therapy in multiple sclerosis patients with high pre-treatment disease activity leads to prompt return to previous disease activity. J Neurol Sci. 2011; 303(1-2):50-52.

31. Kister I, Spelman T, Alroughani R, et al. Discontinuing disease-modifying therapy in MS after a prolonged relapse-free period: a propensity score-matched study. J Neurol Neurosurg Psychiatry. 2016;87(10):1133-1137.

32. Lus G, Signoriello E, Maniscalco GT, et al. Treatment withdrawal in relapsing-remitting multiple sclerosis: a retrospective cohort study. Eur J Neurol. 2016; 23(3):489-493.

33. Fagius J, Feresiadou A, Larsson EM, Burman J. Discontinuation of disease modifying treatments in middle aged multiple sclerosis patients. First line drugs vs natalizumab. Mult Scler Relat Disord. 2017;12:82-87.

34. Bsteh G, Feige J, Ehling R, et al. Discontinuation of disease-modifying therapies in multiple sclerosis-clinical outcome and prognostic factors. Mult Scler. 2017;23(9) 1241-1248.

35. Moisset X, Fouchard AA, Pereira B, et al. Untreated patients with multiple sclerosis: a study of French expert centers. Eur J Neurol. 2021;28(6):2026-2936.

36. Zeydan B, Kantarci OH. Progressive forms of multiple sclerosis. Neurol Clin. 2018; 36(1):163-171.

37. Tomassini V, Fanelli F, Prosperini L, Cerqua R, Cavalla P, Pozzilli C. Predicting the profile of increasing disability in multiple sclerosis. Mult Scler. 2019;25(9): 1306-1315.

38. Weideman AM, Tapia-Maltos MA, Johnson K, Greenwood M, Bielekova B. Metaanalysis of the age-dependent efficacy of multiple sclerosis treatments. Front Neurol. 2017;8:577.

39. Eden D, Gros C, Badji A, et al. Spatial distribution of multiple sclerosis lesions in the cervical spinal cord. Brain. 2019;142(3):633-646.

40. Kerbrat A, Gros C, Badji A, et al. Multiple sclerosis lesions in motor tracts from brain to cervical cord: spatial distribution and correlation with disability. Brain. 2020, 143(7):2089-2105.

41. Lublin FD, Reingold SC, Cohen JA, et al. Defining the clinical course of multiple sclerosis: the 2013 revisions. Neurology. 2014;83(3):278-286. 


\section{Neurology \\ Neuroimmunology \& Neuroinflammation}

Prognostic Accuracy of NEDA-3 in Long-term Outcomes of Multiple Sclerosis Luca Prosperini, Serena Ruggieri, Shalom Haggiag, et al.

Neurol Neuroimmunol Neuroinflamm 2021;8;

DOI 10.1212/NXI.0000000000001059

This information is current as of August 9, 2021

\section{Updated Information \& Services}

References

Citations

Subspecialty Collections

Permissions \& Licensing

Reprints including high resolution figures, can be found at: http://nn.neurology.org/content/8/6/e1059.full.html

This article cites 41 articles, 2 of which you can access for free at: http://nn.neurology.org/content/8/6/e1059.full.html\#\#ref-list-1

This article has been cited by 1 HighWire-hosted articles: http://nn.neurology.org/content/8/6/e1059.full.html\#\#otherarticles

This article, along with others on similar topics, appears in the following collection(s):

Multiple sclerosis

http://nn.neurology.org//cgi/collection/multiple_sclerosis

Information about reproducing this article in parts (figures,tables) or in its entirety can be found online at:

http://nn.neurology.org/misc/about.xhtml\#permissions

Information about ordering reprints can be found online: http://nn.neurology.org/misc/addir.xhtml\#reprintsus

Neurol Neuroimmunol Neuroinflamm is an official journal of the American Academy of Neurology.

Published since April 2014, it is an open-access, online-only, continuous publication journal. Copyright

Copyright (C) 2021 The Author(s). Published by Wolters Kluwer Health, Inc. on behalf of the American

Academy of Neurology.. All rights reserved. Online ISSN: 2332-7812.

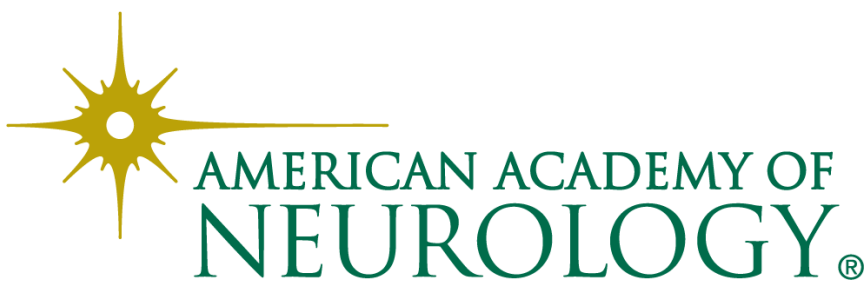

